triol head group of each molecule is embedded in the ethylene oxide chain of the other.

J. D. BiRCHALL

A. J. HOWARD

Imperial Chemical Industries Ltd,

Mond Division,

Research and Development Department,

Runcorn, Cheshire, UK

Received 22 November 1976; accepted 11 January 1977.

1 Kantor, S. W. J. Am. chem. Soc. 75, 2712-4 (1953).

2 Hyde, J. F. J. Am. chem. Soc. 75, $2166-7$ (1953).

Takiguchi, T. J. Am. chem. Soc.81, 2359-61 (1959).

4 ller, R. K. The Colloid Chemistry of Silica and Silicates (Cornell University Press, Ithaca, 19:5).

\section{Palaeomagnetic field intensity variation recorded in a Brunhes epoch deep-sea sediment core}

DEEP-SEA sediments have been shown to possess a natural remanent magnetisation (NRM) that often can be attributed to the statistical alignment of detrital magnetic grains in the Earth's magnetic field at or shortly after the time of their deposition',2. In favourable circumstances this remanence can be interpreted as a record of palaeomagnetic field behaviour ${ }^{3,4}$. In the study reported here we have attempted to describe relative variations in palaeomagnetic field intensity on a time scale of $10^{4}-10^{5} \mathrm{yr}$, during the past $700,000 \mathrm{yr}$, using the palaeomagnetic record of deep-sea sediment piston core RCl0-167 $\left(33^{\circ} 2^{\prime} \mathrm{N}\right.$, $150^{\circ} 23^{\prime} \mathrm{E}$ ), which has an exceptionally thick section of sediment deposited during the Brunhes normal polarity epoch $^{3}$ (Fig. 1). After subtracting the stratigraphic contribution of several distinct volcanic ash layers interspersed with the otherwise uniform pelagic sediment ${ }^{n}$, we calculate an average deposition rate of $2.1 \mathrm{~cm} \mathrm{kyr}^{-1}$ between the adjusted level $(1,470 \mathrm{~cm})$ of the Brunhes-Matuyama boundary $(t=700,000 \mathrm{yr})$ and the top of the core, assumed $t=0$ yr. A $2-\mathrm{cm}$ thick sample, representing about $1,000 \mathrm{yr}$ of deposition, was taken at an average interval of $3.3 \mathrm{~cm}$ (representing about $1,600 \mathrm{yr}$ ). This sampling placed a theoretical limit of $3,000-4,000 \mathrm{yr}$ on the period of a resolvable sinusoidal variation.

Progressive alternating field (AF) demagnetisation of the NRM in 12 pilot samples showed consistent directions of magnetisation, to within $10^{\circ}$ of the initial value, with demagnetisation up to $400 \mathrm{Oe}$. The mean remanent inclination after $150-\mathrm{Oe} \mathrm{AF}$ is $51.2^{\circ}$, close to the expected dipole inclination $\left(52.4^{\circ}\right)$ for the core site latitude. The median demagnetising field (MDF; peak AF required to remove half the initial remanence) is high and relatively uniform, averaging $270 \pm 40 \mathrm{Oe}$ (s.d.). The total magnetic coercivity distribution was investigated by progressive $\mathrm{AF}$ demagnetisation of an anhysteretic remanent magnetisation (ARM; imparted in a 1.0-Oe direct field coaxial with a 1,000-Oe AF) and an isothermal remanent magnetisation (IRM; imparted in a $1,000-\mathrm{Oe}$ direct field). The average MDF values for the 12 specimens are $230+15$ Oe for ARM and $170+25$ Oe for IRM.

On the basis of these experiments we conclude that: (1) the NRM has a high magnetic stability with little contribution from unstable magnetic components; (2) the small scatter in MDF values for NRM, ARM and IRM shows that the magnetic coercivity spectrum is quite uniform over the length of the core; (3) the high stabilities of remanence and the relative stabilities of ARM and IRM ${ }^{7}$ are indicative of fine-grained magnetic carriers; (4) the coercivity spectrum of NRM is more closely approximated by ARM than by IRM in this sediment.

We assume that the magnetisation acquisition process was the same at each stratigraphic level in the sediment and that the intensity of NRM is only a function of palaeofield strength and the magnetic mineral concentration. The variation with stratigraphic level in the sediment (hence age) of NRM intensity, normalised to take into account fluctuations in magnetic mineral concentration, then might provide a record of relative variations in palaeomagnetic field intensity. We do not deal explicitly with the still poorly understood details of the magnetisation acquisition process in the sediment, and so absolute values of palaeofield strength are not obtained directly by this method. A similar approach has been used to describe palaeofield intensity variations across magnetic polarity transitions in deep-sea sediment cores ${ }^{\mathrm{x} . \mathrm{g}}$.

Because of our conclusion (4) above, we have chosen to use the intensity of $A R M$ as a relative measure of the quantity of magnetic mineral carrying the NRM. The variation with depth in this core of ARM, however, is similar to that of initial susceptibility (Fig. 1). Together they provide an internally consistent record of fluctuating magnetic mineral concentration. This correspondence supports our inference of a coercivity spectrum that is uniform over the core length since the magnitude of ARM and initial susceptibility each are affected preferentially by different magnetic grain size ranges. By assuming that over this sediment core the intensity of NRM is uniformly and directly proportional to the strength of the magnetising field" and to magnetic mineral content as measured by $A^{A R M}{ }^{11}$, the ratio of NRM/ARM should be directly proportional to palaeofield strength alone. In practice, we have used the ratio after partial demagnetisation of each remanence in 150 -Oe $\mathrm{AF}$, to remove any possible unstable magnetic components.

A plot of the ratio of NRM/ARM (partially demagnetised) in the Brunhes section of core RC10-167 is shown in Fig. 2. The data have been interpolated linearly to 512 equally-spaced values (from the 448 samples measured), giving an interpolated interval of $2.9 \mathrm{~cm}$ (or about $1,400 \mathrm{yr}$ ). This was done to facilitate further analysis of the data. The ratio of NRM/ARM has a variation of as much as $100 \%$, but more typically about $50 \%$, about a mean value of 0.10 in the core. The record is nearly stationary as the linear trend is only -0.0036 for $1,470 \mathrm{~cm}$ (or $700,000 \mathrm{yr}$ ). Visually, three wavelength components seem to dominate the record: a broad baseline fluctuation with an apparent wavelength of about half the record length, a variation with an apparent wavelength of about $1 \mathrm{~m}$ which gives the record its dominant character, and last, a short wavelength component that seems to ride on the longer wavelength variations.

A power spectrum analysis was performed on this record to identify better any periodic components. Power spectra were estimated using a direct (fast Fourier transform) method with a cosine-rectangular window, and finally smoothed with a three-point Hanning filter ${ }^{12}$ (Fig. 2). We observe an initial falloff in power to a wavelength of approximately $25 \mathrm{~cm}$ beyond which the spectrum is flatter and approximates the spectrum of white noise. This change in overall slope in the power spectrum may be a function of the remanence acquisition mechanism in these sediments, the periodic content of geomagnetic intensity variations or a combination of these. For example, deep-sea sediments may not acquire a stable remanence at the instant of deposition but rather at, or more importantly, over some depth below the sediment-water interface ${ }^{1,2}$. The record of palaeomagnetic field variations with periodicity of the order of the time in which stable remanent magnetisation is acquired will tend to be obscured. On the other hand, 


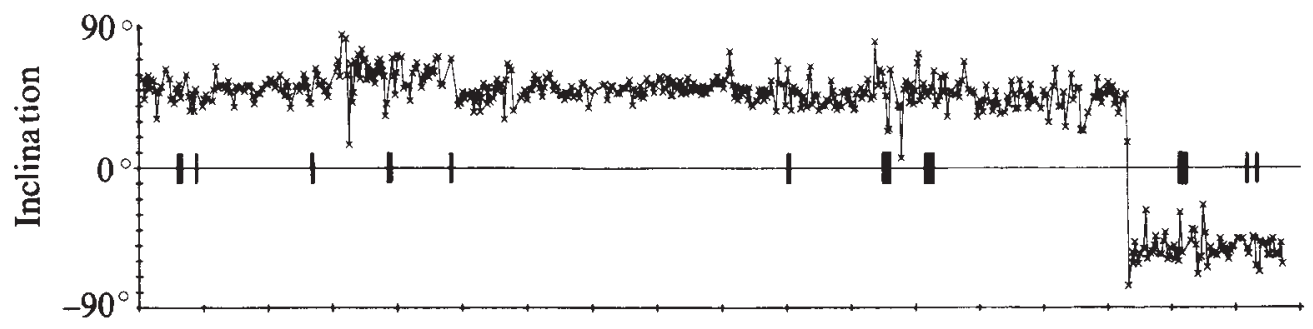

Fig. 1 Inclination direction and intensity of natural remanent magnetism (NRM) against depth in deep-sea sediment core RC10-167. Change in sign of inclination at 15.3- $\mathrm{m}$ depth is interpreted as the Brunhes-Matuyama magnetic reversal boundary ${ }^{5}$. Solid bars on axis of inclination plot are the positions of volcanic ash layers ${ }^{6}$. Also shown is the intensity of ARM and the bulk susceptibility $(k)$. The direction and intensity of NRM and the intensity of ARM are after $\mathrm{AF}$ demagnetisation in 150 Oe. Magnetisation units are in c.g.s. $\mathrm{g}^{-1}$.
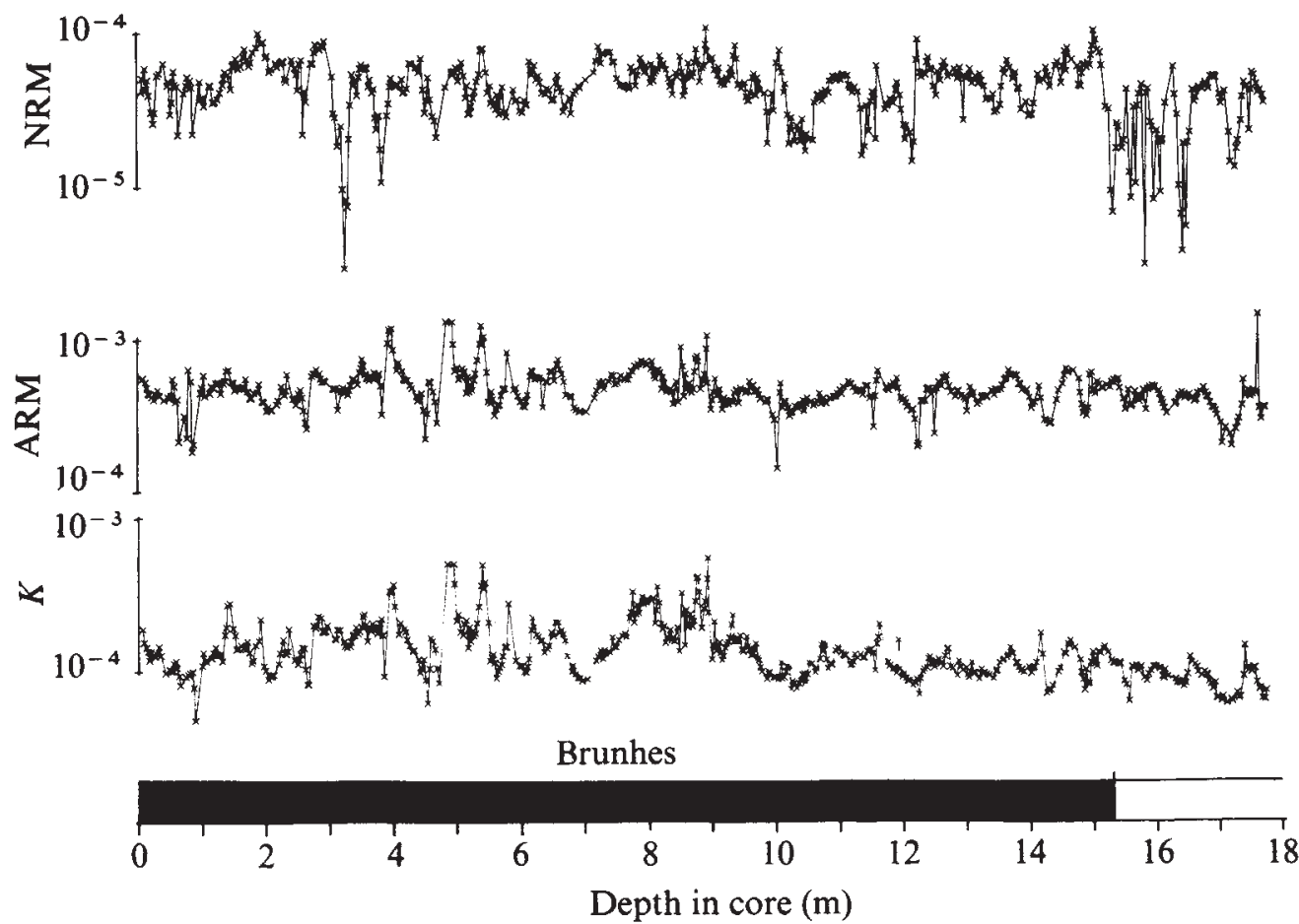

sediment cores with higher deposition rates will need to be studied to determine the contribution of geomagnetic field intensity variations to the shorter wavelength (less than about $12,000 \mathrm{yr}$ ) portion of the spectrum.

The power spectrum is dominated by periodic components with wavelengths of several metres and greater, and a component that forms a more coherent peak centred at a wavelength of about $90 \mathrm{~cm}$. We hesitate to ascribe the longer wavelength variation in NRM/ARM to that of palaeomagnetic field intensity. Our record is too short to evaluate such an apparent long period variation and it may reflect some long term lithological or diagenetic control on the remanent magnetism of the sediment that was not effectively normalised by the procedures used. On the other hand, because of its better defined and persistant character in the record, we feel more confident in interpreting the $90-\mathrm{cm}$ wavelength variation in NRM/ARM as a previously undescribed component of secular variation of palaeointensity. Its apparent period is about 43,000 yr.

A bandpass filter centred on this wavelength (Fig. 3) shows that this component has about a $30 \%$ variation about its mean value, an amplitude of magnitude similar to that obtained for palacointensity variation ${ }^{13}$. We note, however, that our interpreted palaeointensity variation has a period about four times greater than previous estimates ${ }^{14}$. This apparent discrepancy may be due to an inadequate definition of variations in the relatively short archaeomagnetic record on which previous estimates of palaeointensity periodicity have been made. On the other hand, it may simply reflect a more complicated variation in palaeo- intensity than previously suspected. The cause of this discrepancy is difficult to resolve, particularly because our record seems to lack sufficient resolution to detect the shorter periodicity of palaeointensity variation (about $10,000 \mathrm{yr}$ ) estimated from the archaeomagnetic record.

The long period and relatively large amplitude of the inferred 43,000-yr palaeointensity variation suggest that it is due primarily to a secular variation in the strength of the main dipole field, and consequently must reflect processes within the Earth's core associated with its generation. Malkus ${ }^{15}$ has proposed that the geomagnetic dynamo may be driven by forces arising from the precession of the Earth's rotational axis. The efficacy of this energy source in driving the geomagnetic dynamo has been questioned by some $\mathrm{e}^{16,17}$ while others ${ }^{15,18}$ maintain that it is the basic driving mechanism (although convection may play some part). The Earth's rotational axis precesses about the normal to ecliptic with a period of about $21,000 \mathrm{yr}$. The angle between the rotational axis and the normal to the ecliptic (the obliquity), however, does not stay constant but varies between approximately $22.1^{\circ}$ and $24.5^{\circ}$, with an average period city of about $41,000 \mathrm{yr}$ (ref. 19). The precessional force on the core can be expected to vary with the obliquity. If precession has a role in driving the geomagnetic dynamo, some sympathetic variation with obliquity might be expected in the Earth's magnetic field. We suggest that the apparent $54,000-\mathrm{yr}$ variation in palaeointensity recorded in $\mathrm{RC10-167}$ is near to the periodicity of obliquity, and reflects the modulation of a precessionallydriven dynamo by changes in the obliquity. 


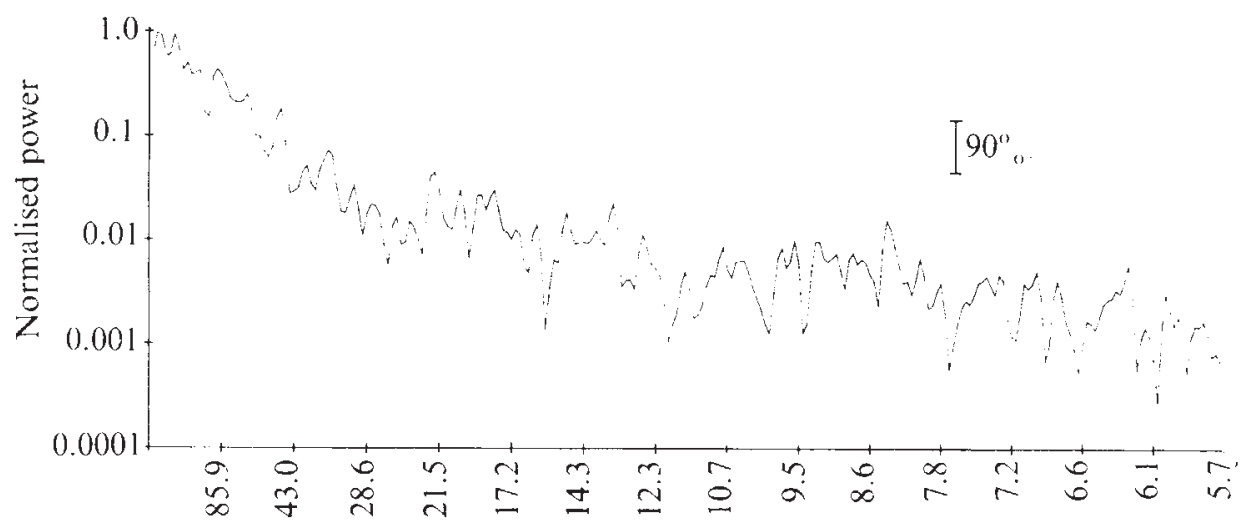

Wavelength $(\mathrm{cm})$

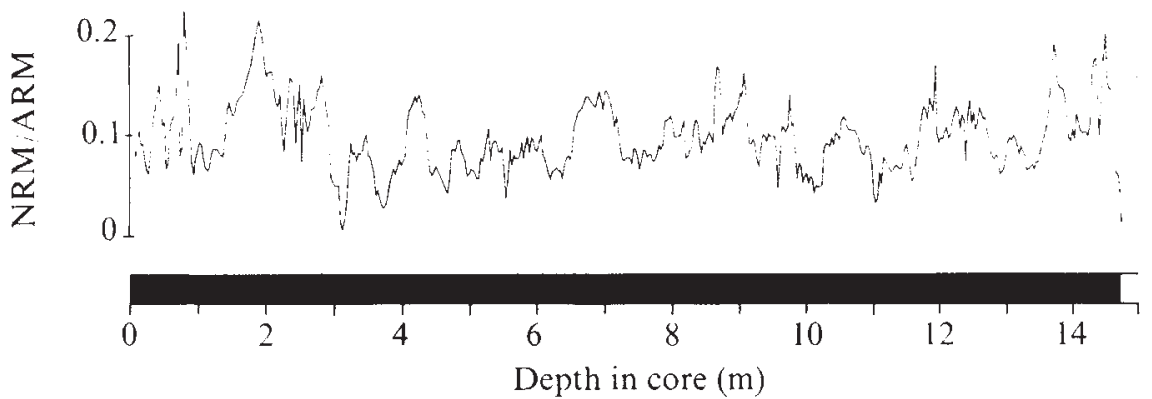

Fig. 2 Lower trace shows the ratio NRM/ARM, against ash-free depth in core RC10-167. The initial set of 448 sample measurements has been interpolated linearly to produce 512 equally-spaced values. Upper trace shows power spectrum of NRM/ARM variation record shown in lower trace, using the fast Fourier transform with a cosine-rectangular window. Estimates of power spectra were smoothed further by a three-point weighted (Hanning) filter. The solid bar is an estimate for the $90 \%$ confidence interval.
Although the magnitude of precessional force may vary by only less than $10 \%$ between times of maximum and minimum obliquity ${ }^{2,}$, much less than the variation in palaeointensity observed here, the relationship between the magnitude of precessional force and the field generated may not be simple. It is possible that some critical amount of energy is required to sustain dynamo action, as found in laboratory dynamo models" ${ }^{21}$. Near this critical value, relatively small variations in contributing forces, such as precession, may have pronounced effects in the magnitude of the generated magnetic field. Figure 3 shows the variation with time in the Earth's obliquity ${ }^{19}$ and in inferred geomagnetic palacointensity as recorded in core RC10-167, assuming a linear time scale between the top of the core and the level of the Brunhes-Matuyama boundary. There seems to be a good correspondence in the expected sense between the palaeointensity and obliquity variations over this time, with obliquity maxima apparently preceeding the inferred intensity maxima by about $5,000 \mathrm{yr}$.

There is no statistical compulsion to accept at the $90 \%$

\section{Time $\left(10^{5}\right.$ yr b.p. $)$}

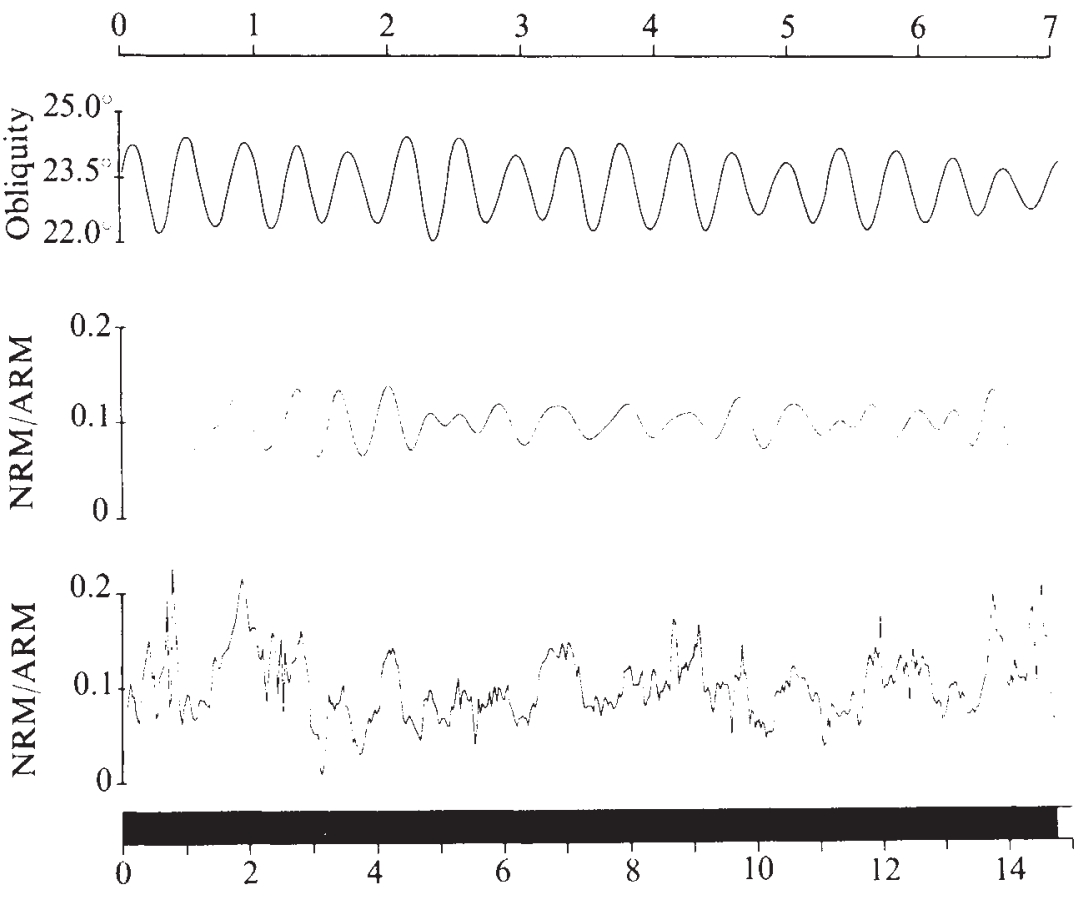

Fig. 3 The variation of NRM/ ARM in core RC $10-167$ (bottom) and the same record (middle) filtered with a cosine-tapered bandpass centred at a wavelength of $90 \mathrm{~cm}$. The time scale is bascd on the assumption of a uniform deposition rate (volcanic ash layers excluded) between the top of the core ( $t \quad 0$ yr) and the level of the Brunhes-Matuyama magnetic reversal boundary $(t-700,000 \mathrm{yr})$. Also shown (top) is the variation with time in the Earth's obliquity from ref. 19 .

Depth in core $(\mathrm{m})$ 
confidence level the existence of the $43,000-y \mathrm{r}$ period in the NRM/ARM record on the hasis of its power spectral density alone. We have some confidence in its reality, however, on the strength of two arguments-the apparent phase coherence with the variation in the Earth's obliquity and the knowledge that such a correlation is not physically absurd. We recognise, however, that results from a single sediment core should be viewed with caution, especially when a global phenomenon is invoked in explanation. It is possible that the inferred palacointensity variation in this core reflects a more local palaeomagnetic field behaviour or a physical property of the sediment, in spite of the magnitude and internal consistency of the observed NRM/ARM variation. Other periodicities of palaeofield intensity may also be involved. These may be difficult to identify with certainty in this core because of the limited record length available to characterise any longer period variations, and because of the restriction imposed by the sampling interval and sediment deposition rate in resolving with confidence any shorter period variations. Nevertheless, we feel that the data described here provide sufficient basis for serious consideration of a $43,000-y r$ variation in the palaeomagnetic field intensity during the past $700,000 \mathrm{yr}$. Confirmation of the existence of such a variation is being sought in a deep-sea sediment core of different lithology and geographically remote from $\mathrm{RC} 10-167$. We point out, however, that of approximately 1,000 cores that we have studied palaeomagnetically from the L-DGO core collection, $R C 10-167$. is unique in having the longest complete record of the Brunhes normal magnetic epoch.

If the apparent correlation between variation in geomagnetic palaeointensity and the Earth's obliquity is substantiated by further work, several implications are apparent. First, it would provide evidence that forces arising from the Earth's precession contribute to driving the geomagnetic dynamo. Second, there is now good evidence that long term climatic variations have been controlled, at least in part, by the Earth's orbital parameters ${ }^{22}$. Therefore, a correspondence between some component of climatic change and variations in the Earth's magnetic field can be expected, due to a possible common mechanism.

K. McCamy provided helpful comments; W. Lowrie and W. I. Donn read the manuscript and D. Lafferty made the measurements. This research was supported by the NSF.

\section{V. KENT}

N. D. OPIYYK :

Lamont-Doherty Geological Observatory of Columbia University,

Palisades, New York 10964

Received 19 July 1976; accepted 11 January 1977.

1 Kent, D. V. Nature 246, 32 (1973).

2 Lovlic, R. Earthplathet. Sci.letr. 21, $315(1974)$

3 Opdyke. N. D. Rev. Geophys. Spuce Phys. 10,213(1972)

${ }^{4}$ Harrison. C. G. A. Earth Sci. Rev 10, I (1974).

5 Opdyke, N. D. \& Foster, J. H. Geol. Soc, Am. Mem. 126.83(1970),

${ }^{6}$ Hays, J. D. \& Ninkovich, D. Geol. Soc. Am. Mem. 126, 263 (1970).

Johnson, H. P., Lowrie, W. \& Kent, D. V. Geophys. J. Roy, astr. Soc. 41, 1 (1975)

Harrison, C. G. A. \& Somayajulu, B. L. K. Namere 212, 1193 (1966)

Opdyke, N. D., Kent. D. V. \& I.owrie. W. Earth planet. Sci. Lett. 20, 315 (1973) (1948, E. A., Murphy, T. \& Torreson, O. W. Terr. Magn. Almos. Elect. 53, 349

11 Levi, S. \& Banerjee, S. K. Earth planet. Sci. Lett. 29, 219 (1976)

12 Bath, M.Spectral Analysis in Geophysics (Elsevier, Amsterdam 1974).

Kono, M

14 Cox, A.J. geophys. Res. 73, 3247 (1968)

15 Malkus, W. V. R.J. scophys. Res. 68, 287 ! (1963); Science 160, 259 (1968)

10 Loper, D. E. Phys. Earrh planet Interiors 11,43(1975).

7 Rochester, M. G., Jacobs, J. A., Smylie, D. F. \& Chong, K. F. Geophys. J. R. astr. Soc. 43,661(1975)

18 Stacey, F. D. Physics of the Earth (Wiley, New York, 1969)

19 Vernekar, A. D. Met. Monogr.12,6(1972)

20 Chappel, J. Farth plamet. Sci.Lett. 26, 370 (1975)

1 Lowes, F. J. \& Wilkinson, I. Nurure 198, $1158(1963)$

22 Hays, J. D.. Imbrie, J. \& Shackleton, N. J. Scit'me' 194, 1121 (1976).

\section{Growth of Pinus pumila and climate fluctuation in Japan}

TRLE-RINC; analysis shows a relationship between annual ring growth and climatic changes in the United States ${ }^{1-3}$ and in the Scandinavian countries. We have measured annual growth in terms of elongation of the terminal shoot of dwarf pine, Pinus pumila (Pallas) Regel, which is common in the alpine zone of Japan and eastern Siberia. This tree was used as the indications of annual growth are clearer than in other plants. The ages of branches used for measurement are $50-200 \mathrm{yr}$, although dating at $>100 \mathrm{yr}$ is difficult. We discuss here the relationship between the fluctuation in annual elongation of dwarf pine and climatic changes in Japan or in higher latitude of Northern Hemisphere.

Elongation of the terminal bud of Pinus pumila starts in early June and terminates in late July. The buds do not elongate further in the following years. Thus annual clongations of the past years are measurable and the number of years so indicated agrees with the number of annual rings at the node. Annual elongation of the main shoot of the pine was measured on trees in many locations of the alpine zone of Japan. There was uniformity of annual variations in elongation among most of populations of different locations (Figs 1 and 2). Such a uniformity was even observed between the populations of Mt Hakusan and Mt

Fig. 1 Annual shoot growth of Pinus pumila in five stands of the alpine zone of Japan. Values for shoot growth are means of $60-20$ plants. The stands are shown in Fig. 2. Correlation coefficient between each two stands: Mt Kisokoma-Mt Norikura, $r=0.396$; Mt Kisokoma-Mt Hakusan, $r=0.873$; Mt Kisokona-Mt Zao, $r=0.785$; Mt Kisokona-Mt Asahi, $r=0.701$; Mt Norikura-Mt Hakusan, $r=0.362$; Mt Norikura-Mt Zao, $r=0.325 ;$ Mt Norikura-Mt Asahi, $r \quad 0.072 ;$ Mt Hakusan-Mt Zao, $r=0.733$; Mt Hakusan-Mt Asahi, $r=0.674$; Mt Zao-Mt Asahi, $r=0.768$. *Hybrid population of $P$. pumila and P. parviftora.

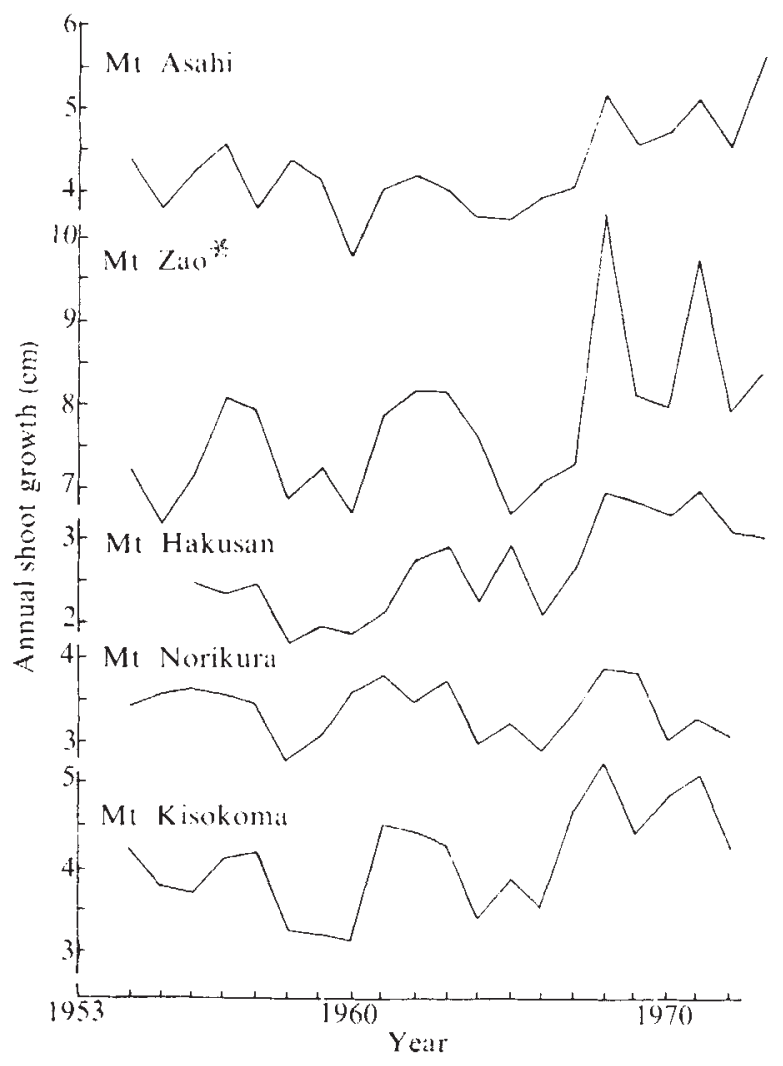

